Khomenko I. P., Tsema E. V., Shapovalov V. Yu., Tertyshny S. V., Yermuraki P. P. Original method of the frontal abdominal wall defect reconstruction using the principle of the reconstructive-restorative surgery. Journal of Education, Health and Sport. 2021;11(1): 372-378. eISSN 2391-8306. DOI http://dx.doi.org/10.12775/JEHS.2021.11.1.037

https://apcz.umk.pl/czasopisma/index.php/JEHS/article/view/JEHS.2021.11.1.037

https://zenodo.org/record/5484260

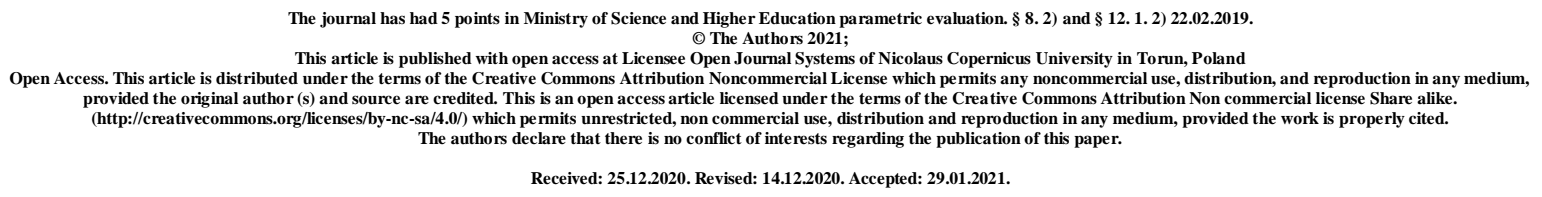

UDC: $617.55-007-089.844$

\title{
ORIGINAL METHOD OF THE FRONTAL ABDOMINAL WALL DEFECT RECONSTRUCTION USING THE PRINCIPLE OF THE RECONSTRUCTIVE-RESTORATIVE SURGERY
}

\author{
I. P. Khomenko ${ }^{1}$, E. V. Tsema ${ }^{1,2}$, V. Yu. Shapovalov ${ }^{3}$, S. V. Tertyshny ${ }^{3}$, P. P. Yermuraki ${ }^{4}$ \\ ${ }^{1}$ National Military Medical Clinical Centre of the Ministry of Defence of Ukraine, Kyiv, \\ Ukraine \\ ${ }^{2}$ National Medical University named after O.O. Bogomolets, Kyiv, Ukraine \\ ${ }^{3}$ South Region Military Medical Clinical Centre of the Ministry of Defence of Ukraine, \\ Odessa, Ukraine \\ ${ }^{4}$ Odessa National Medical University, Odessa, Ukraine
}

\begin{abstract}
The author srepresent the original clinical data devoting to the further progress in reconstructive surgery. The methodology of the staged anterior abdominal wall defect reconstruction using the Keystone method was used firstly.

The aim of the work is to demonstrate the peculiarity of preoperative preparation of patients with the anterior abdominal wall wounds complicated by small intestinal fistulas.

The article uses the clinical materials of the concrete patient treatment in the Department of surgical infection of the South Region Military Medical Clinical Centre (Odessa, Ukraine) using the principle of the reconstructive-restorative surgery.
\end{abstract}


The clinical case of the successful surgical treatment of anterior abdominal wall eventration, resulting from numerous laparotomies with pronounced lateralization of the wound, has shown that the solution to this problem should be based on the principles of reconstructive surgery.

Preoperative modelling of full-layer flaps using a combined technique (infrared camera FLIR and portable Doppler SONO Trax) reduces the risk of necrosis of the movable flap and accelerates the process of closing of the defect of the anterior abdominal wall. Staged ("step-by-step") surgical treatment of the postoperative wound of the anterior abdominal wall by reconstruction via to the Keystone method showed a positive and rapid result of solving such a difficult problem as eventration complicated by small intestinal fistula.

Restoration of the integrity of the anterior abdominal wall should be considered from the standpoint of reconstructive-restorative features.

Keywords: eventration; flap via Keystone method; reconstructive-restorative surgery; original method; frontal abdominal wall defect

Introduction. Eventration is an acute defect in the peritoneum and musculoaponeurotic layer, which creates the conditions for depressurization of the abdominal cavity and the exit of the viscera beyond it $[5,7,9,10]$. In clinical practice, eventration according to domestic and foreign authors is from 0.5 to $2.35 \%$, after repeated laparotomy $12.5 \%[5,6]$, and from the total number of postoperative complications is up to $29 \%$. Postoperative eventration is one of the most dangerous forms of complications in abdominal surgery, in the occurrence of which there is a fairly high mortality, which reaches around 20$30 \%$, and according to some authors - up to $65 \%$. High mortality is also observed in patients in whom eventration is the result of postoperative wound inflammation $[6,7,9,10]$. Such indicators of complications are due to the presence of severe concomitant pathology in patients and complications in the postoperative period in the form of intestinal obstruction, peritonitis, intestinal fistulas [8].

Currently, there are many ways in the world to close the defect of the anterior abdominal wall, but the positive result often takes place due to the preservation of sufficient blood circulation within the wound and surrounding areas. In 2018, the department of surgical infection of the South Region Military Medical Clinical Center (Odessa) performed a reconstruction of the anterior abdominal wall defect in stages via to the Keystone method.

Aim of the work: To demonstrate the peculiarity of preoperative preparation of patients with the anterior abdominal wall wounds complicated by small intestinal fistulas. 
Clinical case: Patient K. M. 59 years old, hospitalized in the department of surgical infection of the South Region Military Medical Clinical Centre on November 26th, 2018 with complaints of a stoma in the right hypochondrium, a large wound on the anterior abdominal wall from which faecal contents are secreted.

Anamnesis: during chemotherapy for cancer of the lower lobe of the left lung T1N0M0, prolongatio morbi, on June 27th, 2018 there were stress ulcers with perforation of the small intestine. On June 30th, 2018 in the Odessa Regional Clinical Hospital the following surgery was performed: upper-middle laparotomy, suturing of the perforated ulcers of the small intestine. On July 30th, 2018 due to the negative dynamics in the postoperative period the following surgery was performed: relaparotomy, resection of the ileum, removal of the terminal ileostomy, on August the $23^{\text {rd }}$ and the $29^{\text {th }}, 2018$ the sutures "cutting" and the resuturing the wound of the anterior abdominal wall was performed. On September the $26^{\text {th }}$, 2018 due to the failure of the ileostomy the reconstruction of the stoma performed. Upon admission to the department of surgical infection of the South Region Military Medical Clinical Centre, the general condition of the patient is of moderate severity, stable. The patient was conscious, time and space oriented. The skin and mucous membranes were pale. Hemodynamics was stable: the blood pressure was $110 / 70 \mathrm{mmHg}$, the pulse was $78 / \mathrm{min}$ and of satisfactory filling. The heart tones were sonorous. Auscultatory: vesicular breath, audible in all parts of lungs, no wheezing. The tongue was clean, moist. The abdomen in the epizootal area was deformed due to the wound, partially participates in the act of breathing, palpatory soft, painful in the area of the wound, the symptoms of peritoneal irritation were negative. Urination was independent, in sufficient quantities. The beating on the lumbar region was not painful on both sides. The stool was mushy, partly via the stoma, partly because of a wound on the anterior abdominal wall.

Status localis: In the epi-mesogastrium, there was an oval wound measuring $20 \times 15 \times 2.5 \mathrm{~cm}$ with expressed lateralization, the bottom of the wound was represented by loops of the intestine over which the granulation tissue formed a "shell", granulation tissue of gray-white colour with yellow-brown areas of (due to faecal masses) contact bleeding, the upper corner of the wound was covered with epithelial tissue. In the lower corner of the wound fistula there was a hole measuring $0.3 \times 0.3 \mathrm{~cm}$ from which comes a moderate amount of small intestine contents. The stoma was located on the right flank in the right hypochondrium, deeply immersed in the anterior abdominal wall, partially functioning with the main volume of feces exiting through the right edge of the wound (Fig. 1). 


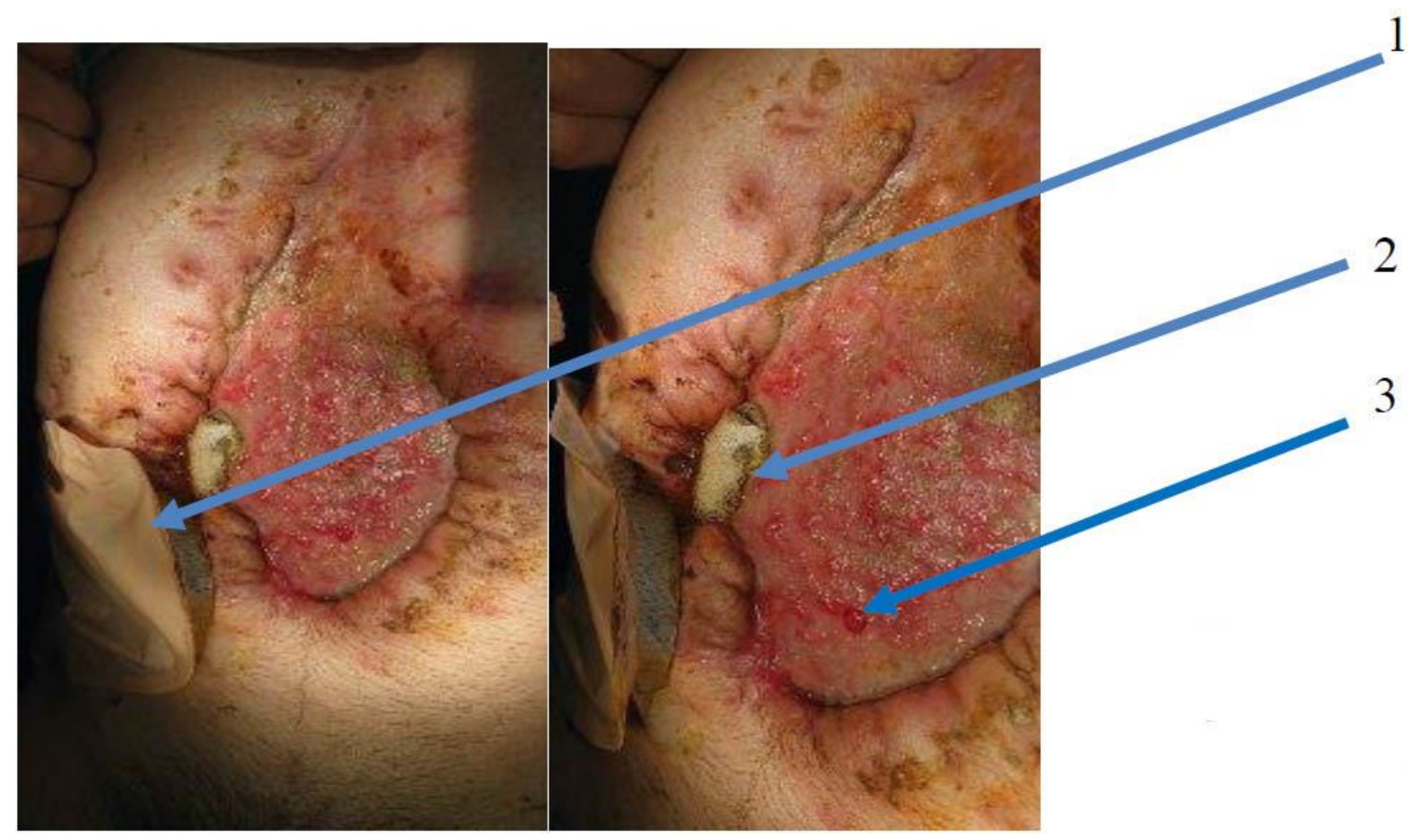

Fig. 1. The view of the frontal abdominal wall off the wounded patient K.

Indications: $\quad 1$-ileostomy; 2 - isolation of faecal masses from fistula on the right the edge of the wound; 3 - fistula

In order to reduce the risk of postoperative wound infection, the decision was made to gradually close it. In the preoperative period, anemia and hypoproteinemia were corrected by the infusion of two doses of plasma and erythrocyte mass, identification of the area and size of the Keystone flap by a combined technique (FLIR infrared camera and SONO Trax portable Doppler).

On November the $3^{\text {rd }}, 2018$, the first stage was the surgical treatment of the anterior abdominal wall wound - ultrasonic cavitation of the wound cavity, plastic surgery of the defect via the Keystone flap, suturing of the ileostomy, closure of the fistula with Surgifoam and TAF light bandages was performed. In the postoperative period, the ileostomy opened, the sutures failed, and the closure of the small intestinal fistula was unproductive, but the wound area decreased by $25 \%$ due to the Keystone flap, which was moved from the left flank.

After a long preparation on December, the $17^{\text {th }}, 2018$. the next stage was performed median laparotomy, viscerolysis, opening and rehabilitation of interloop abscesses, right hemicolectomy, "side to side" ileotransversoanastomosis, sanation and drainage of the abdominal cavity. After that - the repeated surgical treatment of the wound of the anterior abdominal wall, ultrasonic cavitation, plastic surgery of the defect via the Keystone flap from 
the right half of the abdominal wall. At this stage, the wound area was closed on $100 \%$ (Fig. 2).

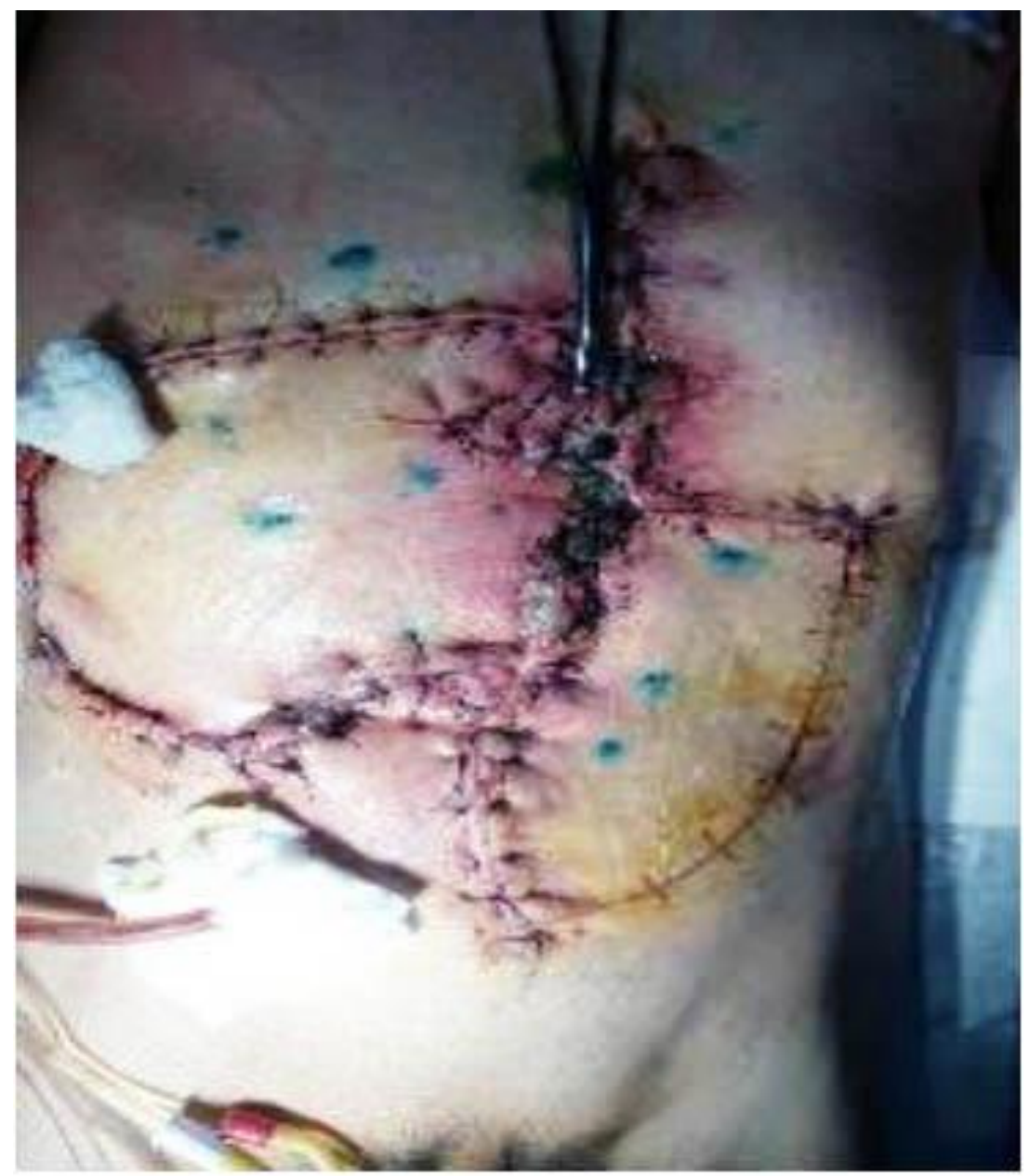

Fig. 2. External view of the anterior abdominal wall after closing the defect with a plastic Keystone flap from the right half of the abdominal wall

But due to infection of the upper third of the postoperative wound the repeated surgical treatment of the wound of the anterior abdominal wall, ultrasonic cavitation, installation of the VAC system with indicators of $-105 \mathrm{mmHg}$ was performed on December, the $26^{\text {th }}, 2018$ in pulse mode for the duration of 48 hours.

On December, the $28^{\text {th }}, 2018$ the VAC system was dismantled, there was no infiltration of the surrounding tissues during the examination, the edges of the wound were pale pink, the granulation tissue was bright pink, the wound bled upon contact. As a result, it was decided to repeat the surgical debridement of the wound of the anterior abdominal wall and the plastic surgery of the defect via the Keystone flap formed by a fragment of soft tissue of the anterior surface of the left half of the chest (Fig. 3). 


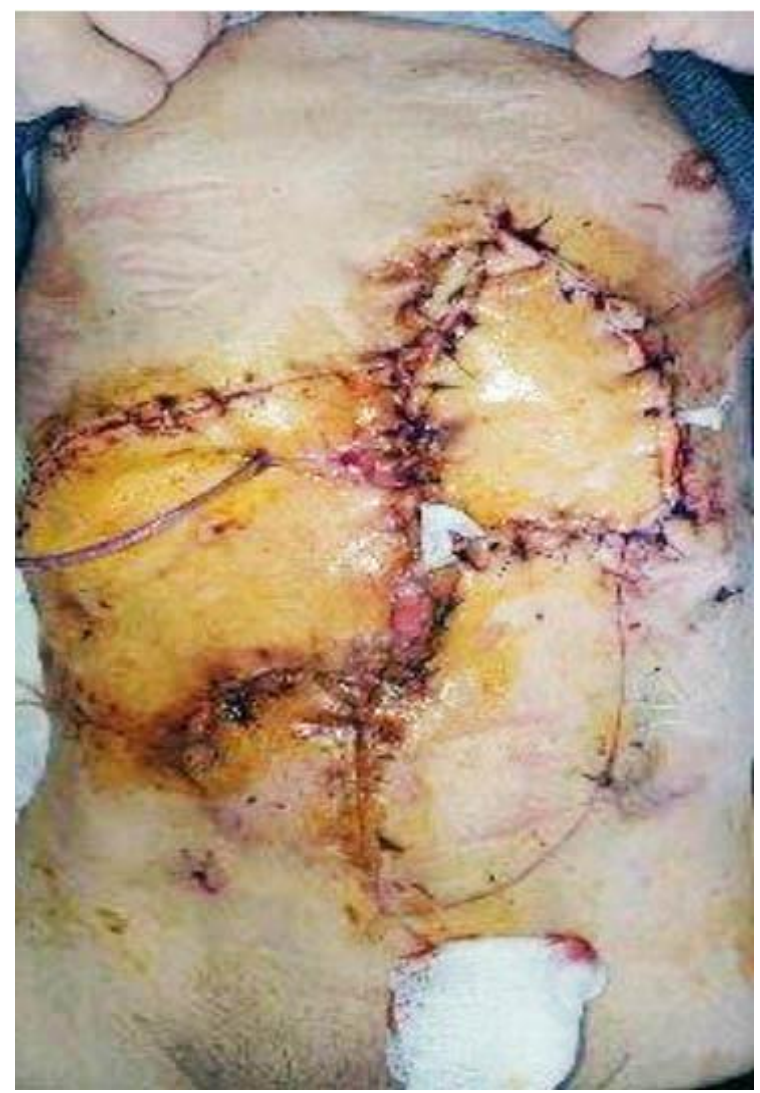

Fig. 3. External view of the anterior abdominal wall after defect re-plasticity using a Keystone flap formed by a fragment of soft tissues of the left part of chest anterior surface

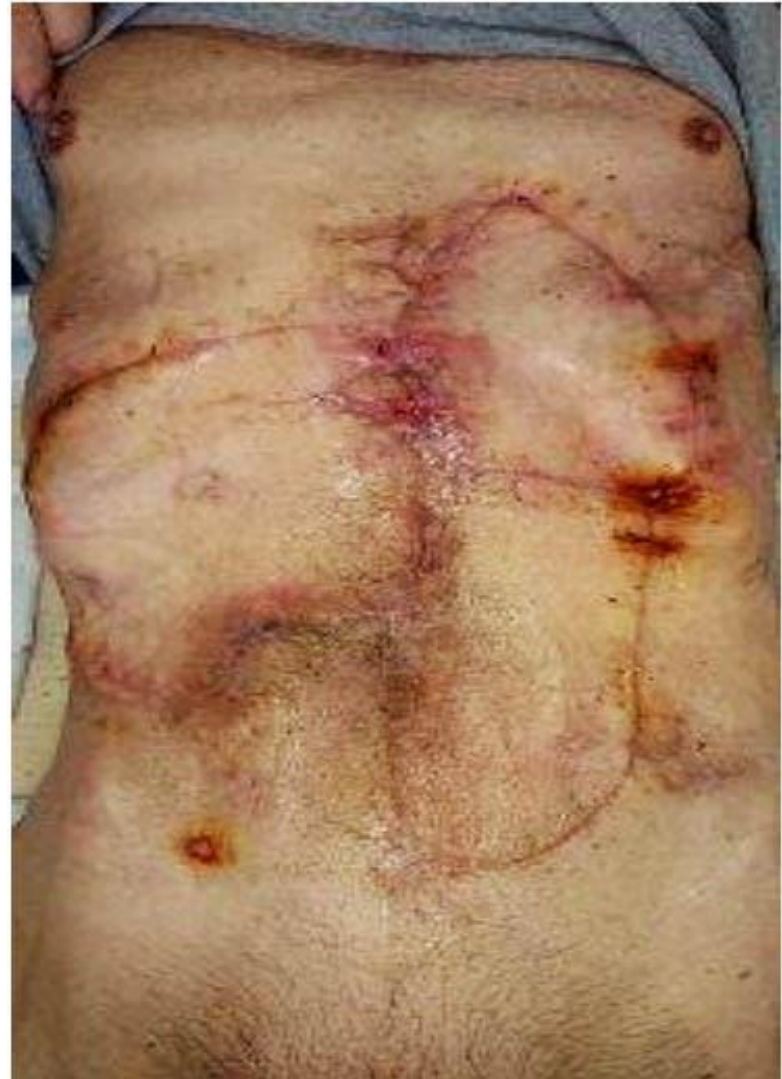

Fig. 4. Patient K. Postoperative period.

The primary tension of the wound

In the postoperative period, the wound healed with primary tension, the patient was discharged with sutures for further outpatient treatment in the clinic at the place of residence (Fig. 4).

On February, the $10^{\text {th }}, 2019$ the patient arrived for a follow-up examination, the postoperative wounds were in the phase of scar organization, without signs of inflammation. Among the complaints there were moderate dyspeptic symptoms in the form of vomiting after eating large amounts of food.

\section{Conclusions}

1. Preoperative modelling of full-layer flaps using a combined technique (infrared camera FLIR and portable Doppler SONO Trax) reduces the risk of necrosis of the movable flap and accelerates the process of closing of the defect of the anterior abdominal wall.

2. Staged ("step-by-step") surgical treatment of the postoperative wound of the anterior abdominal wall by reconstruction via to the Keystone method showed a positive and 
rapid result of solving such a difficult problem as eventration complicated by small intestinal fistula.

3. Restoration of the integrity of the anterior abdominal wall should be considered from the standpoint of reconstructive-restorative features.

\section{References}

1. Gostishchev V.K., Struchkov Yu.V., Revenko N.M. Postoperative eventrations. Surgery Herald. 1982; 4: 132-136 [In Russian].

2. Grigoriev S.G. Treatment and prevention of eventrations. Surgery. Journal of N.I. Pirogov. 1991; 5: 117-120 [In Russian].

3. Zhebrovsky V.V., Mohamen Tom Elbashir Surgery for abdominal hernias and eventrations. - Mopcow, 2002: 96 [In Russian].

4. Myshkin K.I. Relaparotomy after emergency surgery. Surgery. 1989; 2: 39-42 [In Russian].

5. Zhebrovsky V.V., Kaminsky I.V., Torotadze N.N. The use of mesh implants in patients with eventration. Clinical Surgery. 2010; 7: 13-17 [In Russian].

6. Zhitetsky V.V. Prevention and surgical treatment of postoperative events. Medicine today and tomorrow. 2012; 55 (2): 145-149 [In Russian].

7. Boiko V.V., Savvi S.O., Zhitetsky V.V., Novikov Ye.A. Prevention of eventrations after repeated operations on the abdominal organs. Kharkiov Surgical School. 2012; 53 (2): 11-12 [in Ukrainian].

8. Sayenko V.F., Bilyansky L.S. Eventration, causes, prevention, treatment. Clinical Surgery. 2005; 2: 47-51 [In Russian].

9. Shaprinsky V.O., Vorovsky O.O. Causes of evisceration and eventration in elderly and senile patients and methods of their surgical treatment. AML. 2011; XVII: 49-52 [in Ukrainian].

10. Cro C., George K.J., Donnelly J., Irwin S.T., Gardiner K.R. Vacuum assisted closure system in the management of enterocutaneous fistulae. Postgrad. Med. J. 2002; 78: $364-365$.

11. Erdmann D., Drye C., Heller L., Wong M.S., Levin S.L. Abdominal wall defect and enterocutaneous fistula treatment with the Vacuum-Assisted Closure (V.A.C.) system. Plast. Reconstr. Surg. 2001; 108: 2066-2068. 